\title{
EVIDENCE FOR AN ACTIVATING FACTOR FORMED DURING PROSTAGLANDIN BIOSYNTHESIS
}

\author{
Harold w. Cook and William E. M. Lands
}

Department of Biological Chemistry

The University of Michigan

Ann Arbor, Michigan 48104

Received May 27,1975

SUMMARY: The oxygenation of $5,8,11,14$-eicosatetraenoic acid by acetone powder preparations of sheep vesicular glands proceeded with a lag or accelerative phase when inhibitory concentrations of $\mathrm{NaCN}$ were present. This accelerative feature of the reaction suggested that an activating material might be produced as the oxygenation reaction proceeds. When a second addition of fresh enzyme was made to a reaction mixture, the lag phase was as short as in uninhibited controls. This indicated that an activating factor was required for optimal activity of this dioxygenase, and that it accumulated during the oxygenation reaction in the presence of $\mathrm{NaCN}$. The factor was extracted from an aqueous incubation medium with cold diethyl ether. There was a positive relationship between the amount of activating factor added and the resultant increase in the initial velocity of the oxygenation system.

Oxygenation of $5,8,11,14$-eicosatetraenoic acid by enzyme preparations from sheep vesicular glands was suppressed in the presence of functioning glutathione peroxidase activity (1) and, therefore, it was suggested that this phenolactivated enzyme-catalyzed reaction may require a hydroperoxide as an essential intermediate in a kinetic mechanism similar to one proposed for soybean lipoxygenase (2). The soybean lipoxygenase exhibits a lag phase that can be extended by inhibitory concentrations of substrate or glutathione peroxidase and decreased by addition of the product hydroperoxide. The acceleration in velocity can be explained by an activation of the enzyme by a product of the reaction binding to a specific site on the enzyme (2). We have now observed a similar lag phenomenon with the fatty acid dioxygenase of vesicular gland providing evidence that an activating factor needed for the oxygenation step in prostaglandin biosynthesis is produced during the reaction.

Analysis of the changes in reaction velocities was facilitated in our experiments by the continuous recording of the change in oxygen content with time $\left(\mathrm{dO}_{2} / \mathrm{dt}\right)$ with an electronic differentiator attached to the biological oxygen monitor. Examples of the changes in the rate of oxygen consumption during oxy- 
genation of $5,8,11,14-e i c o s a t e t r a e n o i c$ acid with oxygenase preparations from vesicular gland are shown in Fig. 1. In an uninhibited system (A), the reaction velocity reached an optimal value at $12 \mathrm{sec}$ after addition of the final reactant and then decreased. At 9 sec (the earliest time that an accurate measurement of the reaction velocity could be obtained) the velocity was generally $60-75 \%$ of the optimal velocity.

Like several other agents that complex metal ions, sodium cyanide inhibits the oxygenation of arachidonic acid by phenol-activated acetone powder preparations of vesicular gland (3). The optimal rate of oxygen consumption, indicated by the peak of the differentiator tracings (Fig. 1), was reduced considerably in the presence of cyanide. As the concentration of sodium cyanide in the reaction mixtures was increased, the lag period until the optimal velocity was reached became longer (Fig. $1 \mathrm{~A}-\mathrm{E}$ ). For example, with $0.5 \mathrm{~m} M \mathrm{NaCN}$ in the re-

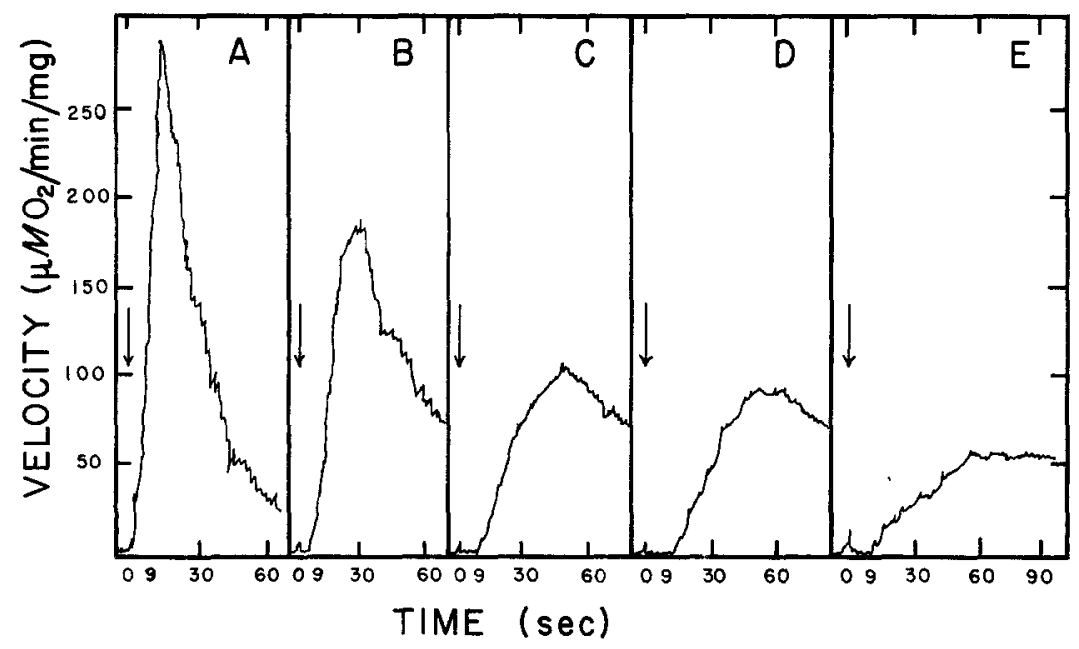

Figure 1. Velocity of oxygen consumption by acetone powder preparation of vesicular gland in the absence and presence of $\mathrm{NaCN}$. The oxygenation of 210 nmoles of $5,8,11,14-e i c o s a t e t r a e n o i c ~ i n ~ 3.0 \mathrm{ml}$ of $0.1 \mathrm{M}$ Tris-HCl (pH 8.5 ) containing $0.67 \mathrm{~m} M$ phenol was determined with an oxygen electrode. The signal was monitored by an electronic differentiator adjusted so that $1 \mathrm{mV}$ on the recorder was equivalent to a rate of $1.74 \mu \mathrm{MO}_{2} / \mathrm{min}$. The concentration of NaCN was $\mathrm{A}-0 ; \mathrm{B}-0.5 \mathrm{~m} M ; \mathrm{C}-1.0 \mathrm{~m} M ; \mathrm{D}-2.0 \mathrm{~m} M ; \mathrm{E}-2.5 \mathrm{~m} M$. At zero time, indicated by the arrows, $250 \mu \mathrm{g}$ of phenol activated acetone powder was used. 
action mixture, the velocity at 9 sec was decreased to 58 from $180 \mu M / \mathrm{min} / \mathrm{mg}$ and the time to optimal velocity increased to $26 \mathrm{sec}$ compared to $12 \mathrm{sec}$ with no NaCN present. There was no detectable velocity at $9 \mathrm{sec}$ with concentrations of NaCN $1 \mathrm{~m} M$ or greater, and the time to optimal velocity extended to more than 60 sec.

After no further oxygen consumption could be detected, another addition of enzyme was made to the reaction mixture to test its suitability for reaction since the original 5,8,11,14-eicosatetraenoic acid concentration had been reduced by less than $20 \%$. This time the optimal velocity was $30-50 \%$ greater (Fig. 2) than that obtained with the first addition of the same amount of enzyme. The lag period following the second addition was brief with all concentrations of NaCN tested, and the velocity at 9 sec was about $65 \%$ of the optimal velocity.

The time until the optimal velocity is reached is a useful index of the severity of the lag phase during which the reaction is accelerating. Often, as seen in Fig. 1 for levels of $\mathrm{NaCN}$ that give greater than $50 \%$ inhibition, this value is an estimation, since it is difficult to determine precisely the point

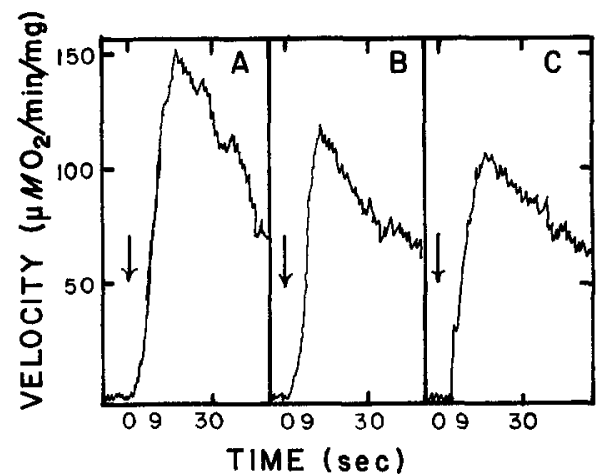

Figure 2. Effect of second addition of enzyme on the reaction velocity in the presence of NaCN. An additional $250 \mathrm{\mu g}$ of phenol-activated acetone powder was added at $10 \mathrm{~min}$ (arrows) to previously reacted mixtures that contained NaCN and 55-60 $\mu \mathrm{M}$ unreacted fatty acid substrate. Reaction mixtures for $\mathrm{A}, \mathrm{B}$ and $\mathrm{C}$ correspond to those in $\mathrm{C}, \mathrm{D}$ and $\mathrm{E}$ of $\mathrm{Fig}$. 1, respectively. 
on the differentiator tracing where the velocity begins to decline. Nevertheless, differences are often great enough to make the values of time to optimal velocity a convenient indication of the lag phenomenon. The velocity at 9 sec, which potentially is useful in quantitating the amount of activator initially present in the reaction mixtuxe (4), can be determined accurately from the differentiator tracings. Observed times to optimal velocity and velocities at 9 sec determined for first addition of enzyme in the presence of $0-2.5 \mathrm{~m} M \mathrm{NaCN}$ and for second addition of enzyme $10 \mathrm{~min}$ after the first are summarized in Fig. 3. Although no velocity at $9 \mathrm{sec}$ could be detected with the first addition of enzyme in the presence of $1.0 \mathrm{mM} \mathrm{NaCN}$ or greater, the progressively greater times to optimal velocity indicate progressively greatex inhibition of the oxygenase system. However, with a second addition of enzyme to the reaction mixture; the velocity at 9 sec was consistently about $60 \%$ of the optimal velocity obtained (data not shown), and the time to optimal velocity was brief and unchanged by the cyanide content in all cases. Addition of more NaCN at the time

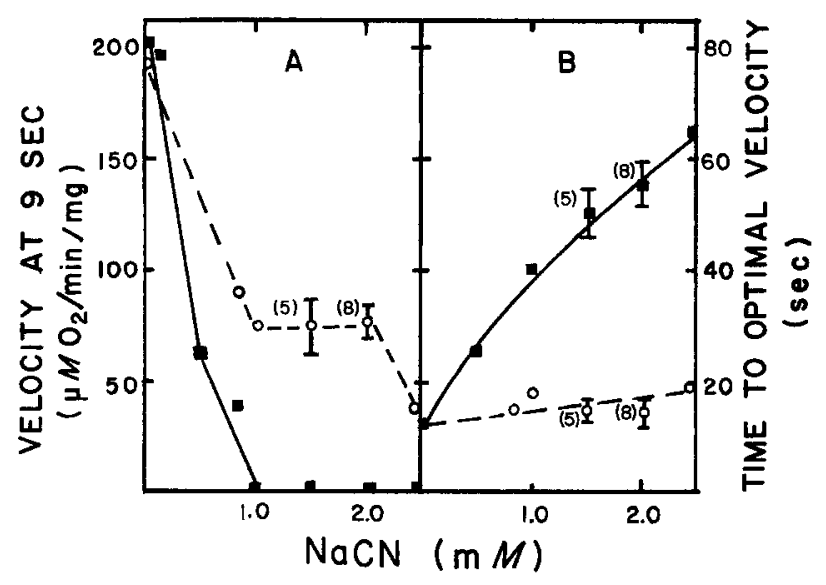

Figure 3. Effect of $\mathrm{NaCN}$ on the velocity at $9 \mathrm{sec}$ and the time to optimal velocity. $250 \mu \mathrm{g}$ of acetone powder preparation of vesicular gland enzyme were added to $3.0 \mathrm{ml}$ of $0.1 \mathrm{M}$ Tris-HCl ( $\mathrm{pH} 8.5$ ) containing $0.67 \mathrm{mM}$ and 210 nmoles of 20:4 ( $\square$ ). After $10 \mathrm{~min}$ another $250 \mathrm{\mu g}$ of enzyme was added ( $\mathbf{0}-\mathbf{O}$ ). velocity at $9 \mathrm{sec}(\mathrm{A})$ and time to optimal velocity (B) were determined from differentiator tracings as described in the text. Bars represent SEM for the number of experiments indicated in brackets. 
of second addition of enzyme to increase the total amount to 2-4 $\mu M$ NaCN generally resulted in only a slightly lower (5-10\%) optimal velocity and a 10-30\% lower velocity at $9 \mathrm{sec}$ compared to values with no additional NaCN. Addition of more fatty acid substrate at that time did not alter either the optimal velocity or velocity at $9 \mathrm{sec}$. A TLC analysis of the products formed in the presence of $2 \mathrm{~m} M \mathrm{NaCN}$ indicated that greater than $60 \%$ of the total reaction products corresponded to prostaglandin $\mathrm{E}_{2}$ and $\mathrm{F}_{2 \alpha}$ standards.

From these results, it appeared that the vesicular gland oxygenase formed an activator that was required for optimal velocity, and that NaCN slowed the formation of this activator as well as the overall reaction rate of the dioxygenase. Apparently, the activating factor accumulated in the reaction mixture so that the second addition of enzyme could operate at near optimal velocity without the need of generating the activator. Thus, the lag was abolished and the velocity at $9 \mathrm{sec}$ was increased greatly. Because a self-catalyzed destruction of enzyme (1) inevitably accompanies activator production during the accelerative phase, the presence of activator allowed a somewhat greater optimal velocity after the second addition than was seen with the first addition of enzyme.

since the activating factor that accumulated in reaction mixtures containing $\mathrm{NaCN}$ was apparently stable for at least $10 \mathrm{~min}$ in the aqueous medium, we tested the effect of adding aliquots of a previous reaction mixture containing $2 \mathrm{~m} M \mathrm{NaCN}$ to fresh assay systems prior to enzyme addition (Fig. 4). The velocity at $9 \mathrm{sec}$ after adding enzyme was proportional to the aliquot of previous reaction mixture in the assay (Fig. 4A). This type of relationship between the amount of activator and the velocity af $9 \mathrm{sec}$ was similar to that found for the activation of soybean lipoxygenase (4). In addition, the optimal velocity attained by a given amount of enzyme was little altered except that a $3.0 \mathrm{ml}$ aliquot gave an increase of about $20 \%$ even though the final concentration of $\mathrm{NaCN}$ in the assay was $4.0 \mathrm{~m} M$. In accord with the increased initial velocities, the time required to reach optimal velocity became shorter as the amount of added reaction mixture was increased (Fig. 4B). 


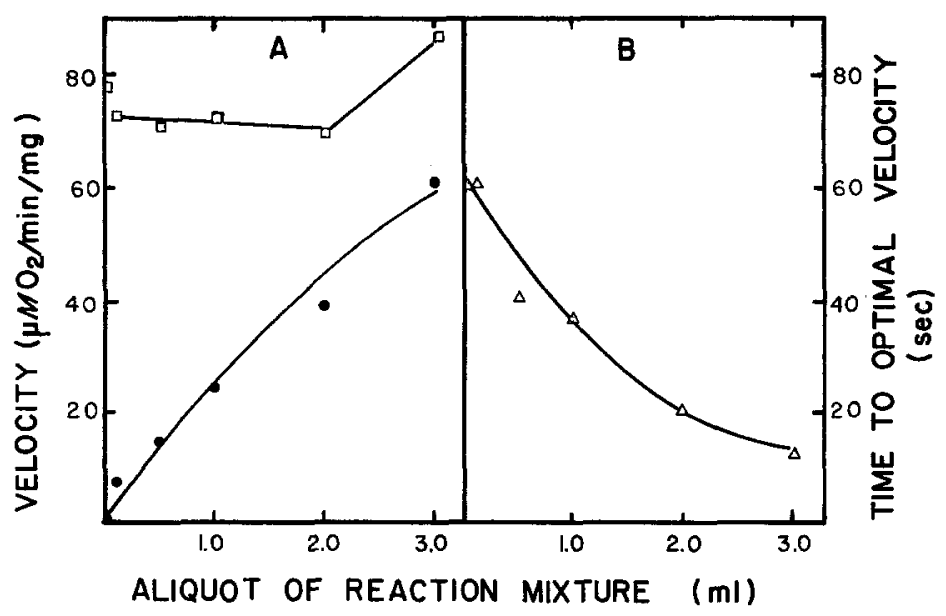

Figure 4. Effect of aliquots of a previous reaction mixture on reaction velocity. Initially $250 \mathrm{\mu g}$ of a phenol-activated acetone powder preparation was incubated in $3.0 \mathrm{ml}$ of $0.1 M$ Tris-HCl (pH 8.5) containing $0.67 \mathrm{~m} M$ phenol, $2 \mathrm{~m} M$ $\mathrm{NaCN}$ and $70 \mu M 5,8,11,14$-eicosatetraenoic acid. Aliquots of this reaction mixture were added to 210 nmoles of $5,8,11,14$-eicosatetraenoic acid with $2 \mathrm{~m} M \mathrm{NaCN}$ in $3.0 \mathrm{ml}$ final volume. Reaction was initiated by addition of $250 \mathrm{\mu g}$ fresh enzyme. A. $\mathbf{D - D}$ optimal velocity, $\mathbf{0}-\mathbf{O}$ velocity at $9 \mathrm{sec} ; \mathrm{B} . \Delta-\Delta$ time to optimal velocity.

Reaction mixtures similar to those above were incubated and treated with diethyl ether. Aliquots of this organic extract were evaporated and assayed for their ability to alter the reaction velocity of enzyme in the presence of $2 \mathrm{~m} M \mathrm{NaCN}$. The effectiveness of these aliquots was compared to that for aliquots of an extract of an incubation of enzyme and substrate with no NaCN present or

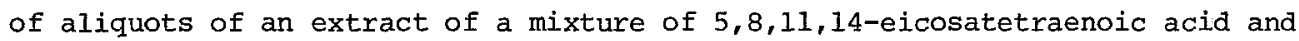
$2 \mathrm{~m} M \mathrm{NaCN}$ in the absence of enzyme (Fig. 5). Values for the latter material indicated the background level for the system and only slight increases in the velocity at 9 sec occurred with aliquots of the extract from this mixture; the maximum effect was to allow a velocity at $9 \mathrm{sec}$ that was $15-20 \%$ of the optimal velocity and in all cases the time to optimal velocity was $55-60$ sec. With increased aliquots of the ether extracts from reaction mixtures that contained no $\mathrm{NaCN}$, there was a 1 to 6 fold greater increase in the velocity at 9 sec and a greater decrease in the time until the optimal velocity was reached. A more 


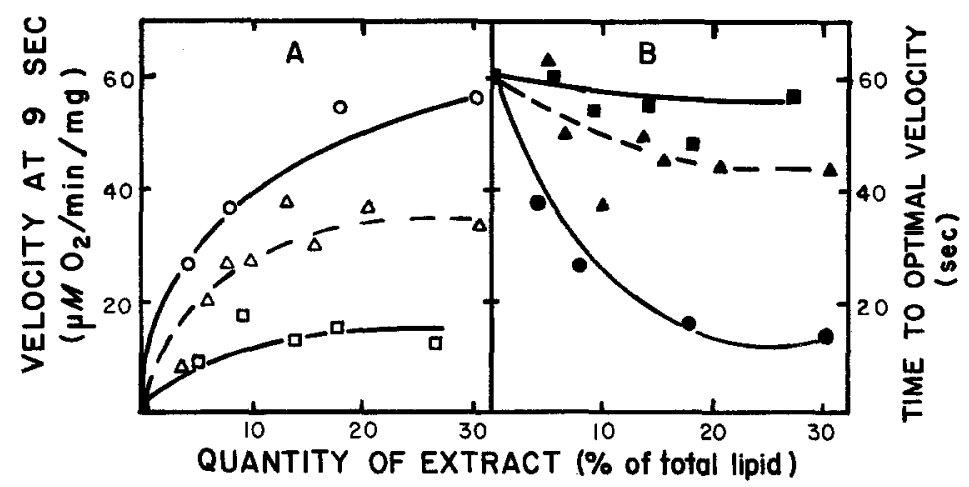

Figure 5. Assay of diethyl ether extracts of reaction mixtures for ability to alter the reaction velocity. Diethyl ether extracts were obtained from preincubations of $1.0 \mu$ mole of $[1-14 \mathrm{C}] 5,8,11,14$-eicosatetraenoic acid in $10 \mathrm{ml}$ of $0.1 M$ Tris-HCl ( $\mathrm{pH}$ 8.5) containing $0.67 \mathrm{~m} M$ phenol that were carried out as follows: A. $7.5 \mathrm{mg}$ of phenol-activated acetone powder preparation for $2 \mathrm{~min}$. B. $7.5 \mathrm{mg}$ of phenol-activated acetone powder preparation and $2 \mathrm{mM}$ NaCN for 2 min. C. $20 \mu$ moles $\mathrm{NaCN}$ followed by $7.5 \mathrm{mg}$ enzyme aftex the mixture was quenched. All reactions were terminated by addition of $30 \mathrm{~m} M$ citric acid. The aqueous mixtures were extracted twice with $20 \mathrm{ml}$ diethyl ether at $0^{\circ}$ and dried over $\mathrm{Na}_{2} \mathrm{SO}_{4}$. After filtering, the solvent was removed under vacuum. Aliquots of the lipid extract were suspended in buffer in reaction chambers. Assay mixtures contained $3.0 \mathrm{ml}$ of $0.1 M$ Tris-HCl (pH 8.5) with $0.67 \mathrm{~m} M$ phenol, $2 \mathrm{~m} M$ NaCl and $50 \mu M 5,8,11,14$-eicosatetraenoic acid. Reaction was initiated by addition of $250 \mu \mathrm{g}$ enzyme. Quantity of extract assayed was determined as a percentage of total in the preincubation mixtures: A. $\Delta-\Delta$, velocity at 9 sec; $\Delta-\Delta$, time to optimal velocity; B. $\mathbf{0}-\mathbf{0}$, velocity at 9 sec; - time to optimal velocity; C. $\mathbf{0}-\mathbf{0}$, velocity at 9 sec; $\mathbf{0}$, time to optimal velocity.

dramatic effect was observed with the extract from the incubation mixture containing $2 \mathrm{~m} M \mathrm{NaCN}$. There was an apparent hyperbolic relationship between the quantity of extract assayed and the velocity observed at $9 \mathrm{sec}$ and, when 18\% of the total extract was assayed, the velocity at $9 \mathrm{sec}$ was $68 \%$ of the optimal velocity reached by $16 \mathrm{sec}$ after initiation of reaction. These latter values for velocity at $9 \mathrm{sec}$ and time to the optimal velocity closely corresponded to those obtained with the second addition of enzyme to a reaction mixture containing $2 \mathrm{~m} M \mathrm{NaCN}$ (see Fig. 3). Thus, the activating factor was organic in nature and was stable enough to permit extraction from an aqueous reaction mixture with diethyl ether at $0^{\circ}$. Clearly, the stimulatory effect of this material on the reaction velocity of an acetone powder preparation was proportional to the concentration of factor. 
It seems that an activating factor essential to oxygenation may be produced during all fatty acid dioxygenase reactions. With $5,8,11,14$-eicosatetraenoic acid and oxygenase preparations from vesicular glands, the production apparently occurs very rapidly in the absence of sodium cyanide, or else lower amounts are needed for optimal enzyme activity. On the other hand, the activator seems also to be dissipated relatively quickly in these preparations in the absence of cyanide so that its activation properties are not retained. clearly, further study of the character and specificity of the activating factor produced in reaction mixtures in the presence of $\mathrm{NaCN}$, and possibly other inhibitors, provides a means for a better understanding of the mechanism of the reaction and insight to the possible regulation of prostaglandin biosynthesis in vesicular gland and other tissues.

\section{ACKNOWLEDGEMENT}

This work was supported in part by a grant from the National science Foundation (GB-28663X) and a Medical Research Council of Canada Fellowship (H.W.C.).

\section{REFERENCES}

1. Smith, W. L. and Lands, W. E. M. (1972) Biochemistry 11, 3276-3285.

2. Smith, W. L. and Lands, W. E. M. (1972) J. Biol. Chem. 247, 1038-1047.

3. LeTellier, P. R., Smith, W. L. and Lands, W. E. M. (1973) Prostaglandins 4, 837-843.

4. Cook, H. W. and Lands, W. E. M. (1975), submitted for publication. 